\title{
Procedural justice and intragroup status: Knowing where we stand in a group enhances reactions to procedures is
}

\author{
Jan-Willem Van Prooijen ${ }^{\mathrm{a}, *}$, Kees Van den Bos ${ }^{\mathrm{b}}$, Henk A.M. Wilke ${ }^{\mathrm{c}}$ \\ ${ }^{a}$ Department of Social Psychology, Free University Amsterdam, Amsterdam, The Netherlands \\ ${ }^{\mathrm{b}}$ Department of Social and Organizational Psychology, Utrecht University, Utrecht, The Netherlands \\ ${ }^{\mathrm{c}}$ Department of Social and Organizational Psychology, Leiden University, Leiden, The Netherlands
}

Received 24 September 2003; revised 27 September 2004

Available online 10 March 2005

\begin{abstract}
The current research investigates the role of relative intragroup status as a moderator of people's reactions to procedural justice. Based on a review of the procedural justice literature, the authors argue that information about intragroup status influences people's reactions to variations in procedural justice. In correspondence with predictions, two experiments show that reactions of people who have been informed about their intragroup status position (either low, average, or high) are influenced more strongly by voice as opposed to no-voice procedures than people who are not informed about their intragroup status. It is concluded that knowing where we stand in a group enhances reactions to procedural justice.
\end{abstract}

(C) 2005 Elsevier Inc. All rights reserved.

Social justice is an essential element of human life: acts that people consider to be fair or unfair influence their perceptions, attitudes, affective reactions, and behaviors (e.g., Folger, 1984). Considerable social psychological research efforts have therefore been concentrated on the psychology of social justice. One justice concern that people have refers to outcome divisions: people want outcome distributions to be fair. The issue of whether outcomes are fair or unfair is generally referred to as distributive justice (Adams, 1965). Distinct from these distributive justice concerns is the perceived fairness of decision-making processes: people want the processes that lead to decisions (such as decisions about outcome distributions) to be fair. The perceived fairness of decision-making processes is referred to as procedural justice (for overviews, see Brockner \& Wiesenfeld, 1996; Cropanzano, Byrne, Bobocel, \& Rupp, 1997; Folger \&

\footnotetext{
This research was supported by the Netherlands Organization for Scientific Research (the NWO) project number 575-31-015.

* Corresponding author.

E-mail address: jw.van.prooijen@psy.vu.nl (J.-W. Van Prooijen).
}

Cropanzano, 1998; Lind \& Tyler, 1988; Tyler \& Blader, 2000; Tyler \& Smith, 1998; Van den Bos \& Lind, 2002; Van Prooijen, Van den Bos, \& Wilke, 2004b). The distinction between distributive and procedural justice is important, because the classic work of Thibaut and Walker (1975) suggests that people's justice concerns indeed involve questions about both the fairness of outcomes and the fairness of procedures.

Justice is a social phenomenon, because experiences of (in)justice are products of people's interactions with others in social settings (Lind \& Tyler, 1988). More generally, it has been argued that social relationships are interconnected with people's experiences of (in)justice (Folger \& Cropanzano, 1998; Lind \& Tyler, 1988; Tyler \& Lind, 1992; Tyler \& Blader, 2000; Van den Bos \& Lind, 2002). An example of a specific social factor that is related to both distributive and procedural justice is intragroup status (Tyler \& Lind, 1992). Distributive justice researchers have argued that intragroup status differences can influence perceptions of entitlement: people who have high intragroup status may perceive themselves to be more entitled to certain outcomes than 
people who have low intragroup status (e.g., Feather, 1994). As a consequence, differences in outcomes (e.g., salaries) between group members holding different status positions (e.g., assistant vs. full professors) are not necessarily perceived to be unfair. In this way, intragroup status can influence distributive justice judgments (Feather, 1994).

Several authors have stated that intragroup status is related to the psychology of procedural justice as well (Cropanzano, Rupp, Mohler, \& Schminke, 2001; Folger \& Cropanzano, 1998; Lind, 2001; Lind \& Tyler, 1988; Tyler \& Lind, 1992; Van Prooijen, Van den Bos, \& Wilke, 2002). Furthermore, empirical surveys have repeatedly shown significant correlations between perceptions of intragroup status and perceptions of procedural justice (e.g., Tyler, 1989, 1994; Tyler \& Blader, 2002; Tyler, Degoey, \& Smith, 1996). However, several authors have noted that the relation between procedural justice and status is conceptually different from the relation between distributive justice and status. That is, whereas high intragroup status may lead people to feel entitled to desirable outcomes, it has been argued that people at all levels of a status hierarchy feel entitled to fair decision-making procedures (Lind, 2001; Tyler, Boeckmann, Smith, \& Huo, 1997, p. 119). In the following we argue that there are important missing links in scientific knowledge on the relationship between intragroup status and procedural justice. The current research is therefore designed to further explore the relation between intragroup status and procedural justice. Below we review the role of intragroup status in the psychology of procedural justice, and introduce what the current research adds to existing knowledge on this topic.

\section{Procedural justice and intragroup status}

An illustration of a typical procedural justice phenomenon is the finding that people evaluate procedures that allow them an opportunity to voice their opinions in a decision-making process to be more fair than procedures that do not allow them such an opportunity (Folger, 1977). These procedural fairness perceptions can subsequently influence a wide range of human reactions, such as positive and negative affect, the willingness to accept decisions, protest intentions, evaluations of people's relations with authorities, and task performance (Folger, Rosenfield, Grove, \& Corkran, 1979; cf. Greenberg \& Folger, 1983; Lind \& Tyler, 1988; Van den Bos, Wilke, Lind, \& Vermunt, 1998). It has been noted that these voice effects are among the most frequently replicated effects in social psychology (e.g., Brockner et al., 1998; Lind, Kanfer, \& Earley, 1990; Van den Bos, 1999; Van den Bos \& Van Prooijen, 2001).
A specific social factor that has been related to the effects of voice as opposed to no-voice procedures is intragroup status, that is, people's position in a group compared to other members ${ }^{1}$ (Cropanzano et al., 2001; Folger \& Cropanzano, 1998; Lind, 2001; Lind \& Tyler, 1988; Tyler \& Lind, 1992; Tyler \& Blader, 2002; Van Prooijen et al., 2002). The relation between intragroup status and procedural justice is highlighted in the relational model of authority, a group-dynamic procedural justice theory (Tyler \& Lind, 1992; cf. Lind \& Tyler, 1988). Following social identity theory (Tajfel \& Turner, 1979), the relational model has made explicit that people attach importance to being respected members of the social groups they belong to. As a consequence, people search for information about the extent to which they are valued and respected by their fellow group members. Because people tend to regard group authorities as representative for their group (Tyler \& Lind, 1992), fair procedures (such as voice procedures) by group authorities communicate that people are respected and valued members of the social group they belong to (Tyler et al., 1996).

The relational model has stated (among other things) that information about intragroup status influences people's reactions to procedures. More specifically, the relational model has assumed that people want to know where they stand in the group (Tyler, 1989, 1994). In other words, people want to know whether they have high or low intragroup status. People derive such information, the relational model proposes, from the way authorities treat them: if authorities treat people respectfully, people conclude that they have high intragroup status. If authorities treat people rudely, people conclude that they have low intragroup status. Information about intragroup status subsequently shapes people's experiences of and reactions to procedural fairness (Tyler, 1989, 1994; Tyler et al., 1996; Tyler \& Blader, 2002). The relational model thereby assumes two causal relations between intragroup status and procedural justice: procedures influence the emergence of status differentials, and status differentials influence people's perceptions of procedural treatment. We note here that the assumed causal

\footnotetext{
${ }^{1}$ It is important to note here that procedural justice researchers have not defined intragroup status consistently (see Cropanzano et al., 2001; Lind, 2001; Tyler \& Blader, 2002; Van Prooijen et al., 2002). Definitions of intragroup status can broadly be categorized into two classes. First, it has been conceived of as relative standing compared to other group members because of external characteristics, such as performances ("comparative status"; Tyler, 1994; Tyler \& Blader, 2002). Second, intragroup status can be based on internal characteristics, such as values and norms ("autonomous status"; Lind, 2001; Tyler \& Blader, 2002). This latter form is related to perceptions of inclusion in a group (Lind, 2001). In a different paper (Van Prooijen, Van den Bos, \& Wilke, 2004a) we have focused on level of inclusion in a group, which corresponds to autonomous status. In the current paper, we study comparative intragroup status (cf. Tyler, 1994).
} 
effects of status on procedural justice are most central in the relational model. This is evidenced by the fact that the relational model seeks to explain procedural justice judgments, and perceptions of status are assumed to shape such judgments.

In two recent experiments we have investigated the effects of status on people's reactions to procedures (Van Prooijen et al., 2002). In those experiments we proposed an implicit mental relation between status and fairness. Based on the relational model (Tyler \& Lind, 1992; cf. Lind \& Tyler, 1988) and the research that followed from it (Tyler, 1989, 1994; Tyler \& Blader, 2002), we argued that the general concept status is cognitively associated with fairness. More specifically, status is related to the regard and approval that people receive from others (Tyler et al., 1996), and therefore it stands to reason that cognitively activating the general concept status may lead to an increased concern for such regard and approval. Furthermore, people tend to use procedural fairness information to make inferences about the extent to which they are held in regard by others in interpersonal encounters (Tyler \& Lind, 1992; cf. Lind \& Tyler, 1988). From this line of reasoning we inferred that cognitively activating the general concept status would enhance people's reactions to procedures. In correspondence with this, the data of two experiments showed that asking participants two open-ended questions about the general concept status-hence making status a salient issue to participants-enhanced reactions to procedural justice manipulations compared to a control condition in which status was not made salient (Van Prooijen et al., 2002). These data suggested a status salience explanation for the relation between status and procedural justice and, additionally, provided preliminary evidence for the causal order of status shaping people's reactions to procedures.

\section{The current research}

In the current article, we present two experiments in which we provided participants with intragroup status information on three possible levels (high vs. average vs. low), and we included a control condition in which participants' intragroup status was unknown. Furthermore, we manipulated whether or not participants received an opportunity to voice their opinions in a decision-making process (Folger, 1977). With these experiments we would like to contribute in two ways to current knowledge on the relation between intragroup status and procedural justice. As a first contribution, we aim to extend the status salience findings of Van Prooijen et al. (2002): What do the status salience findings imply for situations with intragroup status differences? In the previous status salience experiments we did not explore the effects of intragroup status positions on people's reactions to pro- cedures. However, the relational model argues that intragroup status (and not status salience) determines people's reactions to variations in procedural justice (Lind \& Tyler, 1988; Tyler \& Blader, 2000; Tyler \& Lind, 1992). As a consequence, conceptually it makes good sense to investigate the effects of intragroup status differences on reactions to procedures. Moreover, most status issues in real-life situations can best be characterized in terms of relative intragroup status differences (e.g., being either an assistant professor or a full professor in the same psychology department). Studying the effects of intragroup status differences on reactions to procedures would therefore be worthwhile to further scientists' understanding of procedural justice phenomena in reallife social settings.

To investigate whether status salience causes a relation between intragroup status and procedural justice, we hypothesize a central role for the availability of status information. People do not always know their intragroup status position (e.g., in task groups people do not always know how well others perform, and even if they do performances are not always comparable due to different individual task characteristics). In the current paper, we argue that the availability of status information has consequences for people's reactions to procedures. More specifically, in situations where people are unaware of their intragroup status, status is likely to be less salient than when people did receive direct information about their intragroup status. For example, information that someone is the best, average, or worst performing group member emphasizes the individual's relative status position in the group. It is therefore reasonable to assume that status is more salient in situations where status information is available compared to situations where status information is unavailable. Building on the finding that status salience amplifies reactions to procedures (Van Prooijen et al., 2002), it can therefore be expected that the mere presence of intragroup status information leads to stronger reactions to procedures compared to situations where status information is absent. We therefore predicted that following status information (i.e., information that one has either high, average, or low intragroup status) participants would respond more strongly to voice as opposed to novoice procedures than participants in a control condition in which no status information is provided (Hypothesis 1).

An interesting feature of this hypothesis is that it can be contrasted with different insights derived from other procedural justice theories. More specifically, social-cognitive procedural justice theories such as fairness heuristic theory (e.g., Lind, Kulik, Ambrose, \& De Vera Park, 1993; Van den Bos, Lind, \& Wilke, 2001; Van den Bos, Wilke, \& Lind, 1998) and the uncertainty management model (Van den Bos, 2001; Van den Bos \& Lind, 2002) would lead to different predictions regarding the relation between status and procedural justice. One of the 
propositions of these theoretical frameworks is the fairness substitutability effect (Van den Bos \& Lind, 2002): under conditions of information uncertainty, people start using other information - as heuristic substitutesto assess what is fair. Based on this, it has been argued that people's fairness judgments are strongly affected by procedures in conditions of information uncertainty (Van den Bos \& Lind, 2002). An illustration of the fairness substitutability effect can be found in Van den Bos et al. (1998). These authors showed that people's distributive justice judgments are more strongly affected by procedures if they do not know whether or not an authority can be trusted as compared with situations where they do know that an authority can or cannot be trusted. When we apply this reasoning to the current research, participants experience most information uncertainty in the condition where they are not informed about their status position. As such, it can alternatively expected here that the availability of status information leads to weaker (instead of stronger) reactions to voice as opposed to no-voice procedures compared to situations where status information is absent (Hypothesis $1_{\text {alt }}$.

Besides investigating the effects of the availability of status information as such, a second extension of the literature is that we examine the moderating effects of status differences on reactions to procedures. Based on the current knowledge, it is as yet unclear whether people's reactions to procedures are moderated by specific intragroup status positions. This is problematic, because the literature suggests at least two different predictions regarding whether high versus average versus low status members respond differently to procedures. First, if status salience is the primary explanation of the relation between intragroup status and procedural justice, differences between specific status positions in reactions to voice as opposed to no-voice procedures are not necessarily to be expected (Hypothesis 2). That is, information that someone is the best, average, or the worst performing group member emphasizes one's position in the group, makes status a salient issue to the person, and thus amplifies people's reactions to procedures (cf. Van Prooijen et al., 2002).

However, based on the relational model it can alternatively be expected that people respond differently to procedures as function of specific status positions. After all, the relational model has posited that voice procedures communicate that people are well-respected members of social groups (Lind \& Tyler, 1988; Tyler \& Lind, 1992). Members who have low intragroup status may therefore be more concerned about the fairness of procedures than members with high intragroup status, because low status members are less secure of the extent to which they are respected by their fellow group members than high status members (see also De Cremer, 2002). Thus, it can be hypothesized that voice as opposed to no-voice procedures exert stronger effects on people who are low in status than on people who are high in status (Hypothesis $2_{\text {alt }}$ ).

In both experiments, we tested the hypotheses on one of the most typical dependent variables in procedural justice research: we assessed participants' procedure judgments (Lind \& Tyler, 1988). Specifically, we asked participants how fair they thought the procedure was, how just they thought the procedure was, how appropriate they thought the procedure was, and how satisfied they were with the procedure (cf. Van den Bos \& Lind, 2001).

\section{Experiment 1}

\section{Method}

\section{Participants and design}

We tested the above-mentioned hypotheses in a 4 (intragroup status: high vs. average vs. low vs. unknown) $\times 2$ (procedure: voice vs. no voice) factorial design. A total of 111 students at the Free University Amsterdam (45 men, 66 women), varying in age from 17 to 29 years, voluntarily participated in the experiment. Participants were assigned randomly to conditions. The experiment was preceded by two other, unrelated experiments. The experiments lasted a total of $75 \mathrm{~min}$ and participants were paid 17.50 Dutch guilders (about US \$7.50 at the time this study was conducted) for participation.

\section{Procedure}

On arrival at the laboratory, participants were led to one of 15 separate cubicles. In the cubicles, participants found computer equipment that was used to present the stimulus information and to collect the data. The intragroup status manipulation was introduced by asking participants to imagine the following situation:

You are an employee at a specific department of a factory. Because of your work performance you are the highest / on average / the lowest in status at your department.

The sentence that carried the intragroup status information was omitted in the no-information condition. After this, participants read the procedure manipulation:

The management of the factory has decided to give the employees of your department a once-only financial bonus. The management has decided to give you voice / no voice about the size of the bonus you think you should receive.

Participants then answered the questions pertaining to the dependent variables. The following four procedure judgments were assessed: "How fair was the procedure used to divide the bonus?" $(1=$ very unfair, $7=$ very fair), "How just was the procedure used to divide the bonus?" $(1=$ very unjust, $7=$ very just $)$, "How 
appropriate was the procedure used to divide the bonus?" ( $1=$ very inappropriate, $7=$ very appropriate $)$, and "How satisfied are you with the procedure used to divide the bonus?" $(1=$ very unsatisfied, $7=$ very satisfied). These four items were strongly correlated $(r \mathrm{~s}>.76$, $p s<.001)$. Furthermore, a confirmatory factor analysis showed an excellent fit of a one-factor model, $\chi^{2}(2)=3.13$, ns; NFI = .99; NNFI = .99; CFI $=1.00$. We therefore averaged these four items into a reliable procedure judgments scale $(\alpha=.95)$.

\section{Results}

The cell means and standard deviations are presented in Table 1. A $4 \times 2$ univariate analysis of variance (ANOVA) showed a significant main effect of procedure, $F(1,103)=234.62, p<.001$. This main effect was qualified by the predicted interaction, $F(3,103)=3.80, p<.02$.

To test whether the effect of procedure was significantly stronger among participants who were informed about their intragroup status than among those who were not informed about their intragroup status, we conducted an interaction contrast analysis in which we contrasted the effect of procedure in the intragroup status known conditions (i.e., the high, average, and low status conditions) versus the effect of procedure in the intragroup status unknown condition. This analysis yielded a significant interaction contrast, $F(1,107)=8.79, p<.01$. Furthermore, we tested whether the procedure manipulation exerted different effects in the three status-known conditions by means of a 2 (procedure: voice vs. novoice) $\times 3$ (status: high vs. average vs. low) ANOVA. The interaction was nonsignificant, $F(2,78)=1.36, p>.26$, indicating that the different levels of known status yielded similar procedure effects: participants in the high, average, and low status conditions did not differ in their reactions to the procedure manipulation. Subsequent analyses revealed that the procedure simple main effect was much stronger in the status known conditions, $F(1,107)=221.81, p<.001, \eta^{2}=.68$, than in the status unknown condition, $F(1,107)=25.80, p<.001, \eta^{2}=.19$. In correspondence with Hypothesis 1, these results showed that procedure judgments were influenced more strongly by the procedure manipulation among participants who had been informed about their intragroup

Table 1

Means and standard deviations of participants' procedure judgments as a function of intragroup status and procedure (Experiment 1)

\begin{tabular}{|c|c|c|c|c|c|c|c|c|}
\hline \multirow[t]{3}{*}{ Procedure } & \multicolumn{8}{|c|}{ Intragroup status } \\
\hline & \multicolumn{2}{|c|}{ High } & \multicolumn{2}{|c|}{ Average } & \multicolumn{2}{|l|}{ Low } & \multicolumn{2}{|c|}{ Unknown } \\
\hline & $M$ & $S D$ & $M$ & $S D$ & $M$ & $S D$ & $M$ & $S D$ \\
\hline Voice & 5.64 & 0.88 & 5.80 & 0.89 & 6.25 & 0.77 & 5.54 & 1.13 \\
\hline No voice & 2.59 & 0.93 & 2.48 & 1.46 & 2.29 & 1.26 & 3.48 & 1.02 \\
\hline
\end{tabular}

Note. Higher means indicate more positive procedure judgments. status than among participants who had not been informed about their intragroup status. Furthermore, the finding that the procedure manipulation exerted the same effects in the status known conditions supported Hypothesis 2.

As an aside, the means reported in Table 1 suggest that particularly participants who had received a novoice procedure were influenced by the intragroup status manipulation. In correspondence with this, simple main effect analyses showed that the intragroup status effect was nonsignificant within the voice condition, $F(3,103)=1.22$, ns, but was significant within the novoice condition, $F(3,103)=4.03, p<.01$. To further explore these effects, we contrasted within each procedure condition the reactions of participants who had versus had not information about intragroup status. Results showed that status information did not significantly influence procedure judgments of participants following a voice procedure, $F(1,103)=1.22$, ns, but status information did influence procedure judgments following a no-voice procedure, $F(1,103)=11.50, p<.002$. Thus, being informed about intragroup status predominantly enhanced participants' reactions to no-voice procedures. We revisit this issue in General discussion.

\section{Discussion}

Results of Experiment 1 provide corroborative evidence for Hypothesis 1: people who have information about their intragroup status are more strongly affected in their procedure judgments by variations in voice procedures than people who do not have information about their intragroup status position. These results therefore suggest that information about status enhances people's reactions to procedures. This finding is in correspondence with the relational model (Tyler \& Lind, 1992; cf. Lind \& Tyler, 1988) and suggests that the relation between procedural justice and status differentials in an intragroup setting may be explained because the mere presence of status information amplifies reactions to procedures (cf. Van Prooijen et al., 2002).

Following Hypothesis 2, in the current experiment we did not find significant differences between individuals who knew their intragroup status (i.e., the high vs. average vs. low conditions) in their reactions to voice as opposed to no-voice procedures. This may imply that the primary explanation for the relation between status and procedural justice is salience of status, and not different consequences of various intragroup status positions on reactions to procedures. Before drawing strong conclusions, however, it is important to replicate the findings of Experiment 1 in a second experiment. After all, in Experiment 1 participants imagined themselves to be in a fictitious situation. Based on Experiment 1, we cannot be sure how people would react in a situation in which they really experience status differences and voice or no-voice 
procedures. To establish the robustness of our findings, we tested our hypotheses again in an experiment in which participants directly experienced intragroup status differences and voice or no-voice procedures.

\section{Experiment 2}

In Experiment 2, we used a laboratory group situation (cf. Brewer, 1979) in which participants directly experienced variations in intragroup status and opportunities to voice their opinions. Replication of our results in such an experiential setting would increase our confidence that the findings of Experiment 1 are not artifacts of the scenario methodology, but rather are indicative for the effects of intragroup status on reactions to voice procedures, as we have hypothesized in our general introduction. Dependent measures were the same procedure judgments as in Experiment 1.

An additional aim of the second experiment was to rule out alternative interpretations of our results. We did this in two ways. First, in Experiment 2 we measured a number of constructs that could possibly be associated with the relation between status and procedural justice: procedural entitlement (i.e., the extent to which people perceive themselves as entitled to fair decision-making procedures), belongingness, and expectations of unequal treatment. By measuring these constructs, in Experiment 2 we were able to investigate whether or not the described effects are attributable to other processes than the status salience explanation argued for in the introduction.

Second, we also tried to rule out the alternative explanation that status information may have increased participants' distributive justice concerns. After all, it has been argued before that status differentials may affect what outcomes are perceived as fair: people with high status positions may perceive themselves as more entitled to positive outcomes than people with low status positions (Feather, 1994). Furthermore, procedures may influence participants' perceptions of outcome control (Thibaut \& Walker, 1975): voice procedures may raise the impression that recipients can influence their own outcomes, whereas no-voice procedures may lead people to conclude that they cannot influence their own outcomes. It could therefore be argued that participants' intragroup status position gave them a clearer picture of what outcomes they are entitled to (cf. Feather, 1994), and may thus have increased the need for voice procedures in order to obtain those outcomes. In the second experiment, we have tried to rule out this possibility by allowing participants voice as opposed to no-voice about outcome distributions at the intergroup level whereas manipulating status (high vs. average vs. low vs. unknown) at the intragroup level. More specifically, participants could versus could not voice an opinion about how resources should be distributed between their group and other groups, without referring to how these outcomes would be divided between themselves and other group members. We assumed that intragroup status differentials would not influence people's perceptions of how resources should be distributed between their own group and different groups, and we checked this by analyzing the opinions that participants in the voice conditions expressed.

\section{Method}

\section{Participants and design}

We tested our hypotheses in a 4 (intragroup status: high vs. average vs. low vs. unknown) $\times 2$ (procedure: voice vs. no-voice) factorial design. A total of 171 students at the Free University Amsterdam (41 men and 130 women, varying in age from 17 to 35 years) voluntarily participated in the experiment. The experiment was preceded by another, unrelated experiment. The experiments lasted a total of $1 \mathrm{~h}$ and participants received 12.50 Dutch guilders for participation in the experiments.

\section{Procedure}

Participants were welcomed in the same laboratory and were seated behind the same computer equipment as in Experiment 1. Participants were told that they would participate in a study on how people perform tasks in groups, and that therefore they would work on tasks together with the other participants that were at that moment present in the laboratory. Each participant would work on individual tasks. The performance of each participant would be used to compute one single group performance score. As such, the participants present in the laboratory formed a team. This team was referred to as "The Blue Team" (cf. Van Leeuwen, Van Knippenberg, \& Ellemers, 2003; Van Prooijen et al., 2004a). After this, participants were presented with a blue team logo on the computer screen. Participants were informed that there were currently eight participants in the laboratory and that The Blue Team would therefore consist of eight members (in reality, all stimulus information was preprogrammed; a procedure none of the participants objected to upon debriefing).

Participants were then informed that several teams had previously participated in the experiment. Three of these teams also had eight members. Thus, the current team (the Blue Team) was the fourth team consisting of eight members that participated in the experiment. Furthermore, participants were informed that after all teams were run, a lottery with a prize of 100 Dutch guilders would be held among all participating teams. A number of lottery tickets would be allocated to The Blue Team. Additionally, participants were told that all computers were connected to each other by means of a computer 
network and that the experimenter would send messages to the members of The Blue Team during the experiment. To ensure comprehension of this experimental procedure, we then posed six dichotomous practice questions referring to the procedure. Participants received feedback if they gave an incorrect answer to a question.

After this, the tasks that the participants and their team members would conduct were explained. Participants worked on the tasks in two rounds: a practice round of $2 \mathrm{~min}$ and a work round of $10 \mathrm{~min}$. A figure that consisted of 36 squares was presented on the upper right side of the computer screen. Each square showed one of eight distinct patterns. One of the eight patterns was presented on the upper left side of the screen, and participants had to count the number of squares with this pattern in the figure on the right side of the screen. After the participants had indicated the correct number, another figure was presented. In both the practice and the work round, the number of tasks completed (i.e., the number of figures that participants had counted in that round) and the time remaining were both shown at the bottom of the screen. At the end of the work round, participants were informed that the group performance of The Blue Team was similar to the group performances of the three previous teams that had also consisted of eight members.

We then induced the status manipulation. Participants in the high status condition were informed that with their individual task performance they had contributed the most to the team performance and that they were therefore the highest in status within The Blue Team. Participants in the average status condition were informed that with their individual task performance they had contributed on average to the team performance and that they were therefore on average in status within The Blue Team. Participants in the low status condition were informed that with their individual task performance they had contributed the least to the team performance and that they were therefore the lowest in status within The Blue Team. In the no-information condition, participants did not receive such information concerning their individual contribution to the team performance and their corresponding status position.

After this, we administered the procedure manipulation to the participants. In the voice condition, the experimenter ostensibly asked participants by means of the computer network to give their opinion about the percentage of lottery tickets that they thought should be allocated to The Blue Team. These participants were subsequently asked to type in the percentage of the lottery tickets that would be divided among the four teams they thought should be allocated to The Blue Team (this percentage is subsequently referred to as participants' "voiced opinions"). In the no-voice condition, the experimenter ostensibly informed participants by means of the computer network that they would not be asked to give their opinion about the percentage of lottery tickets that they thought should be allocated to The Blue Team. These participants were subsequently not asked to type in the percentage of the lottery tickets that would be divided among the four teams they thought should be allocated to The Blue Team.

\section{Dependent measures}

The participants then answered the questions pertaining to the dependent measures and the manipulation checks. We solicited participants' procedure judgments the same as in Experiment 1 by asking four similar questions about the procedure used to divide the lottery tickets. As in Experiment 1, these four items were strongly correlated $(r s>.74, p s<.001)$. Furthermore, a confirmatory factor analysis showed an excellent fit of a one-factor model, $\chi^{2}(2)=1.94$, ns.; $\mathrm{NFI}=1.00 ; \mathrm{NNFI}=1.00$; $\mathrm{CFI}=1.00$. In correspondence with Experiment 1, we therefore decided to combine these items into one general and reliable measure of procedure judgments $(\alpha=.94)$.

To get a better sense of the effects of the status manipulation, and to rule out alternative explanations, we also assessed a number of additional measures. First, we measured participants' sense of procedural entitlement. More specifically, participants were asked to what extent they agreed to the following two questions $(1=$ not at all, $7=$ very $m u c h)$ : "Because of my performance on the tasks, I think that I am entitled to correct treatment during the course of the experiment" and "Because of my performance on the tasks, I believe that I deserve correct treatment during the course of the experiment." These two items were averaged into a reliable entitlement scale $(\alpha=.95)$. Furthermore, we assessed participants' sense of belongingness in the group and their identification with the group. To assess belongingness, we used a modified version of the inclusion of other in the self-scale (Aron, Aron, \& Smollan, 1992). That is, participants were graphically presented with seven figures, each containing two Venn diagrams. One Venn diagram represented the self and the other represented The Blue Team. The figures varied regarding the amount of overlap between the two Venn diagrams, and participants had to choose what figure best described their relation to The Blue Team (for details, see Aron et al., 1992). To assess identification, we asked to what extent participants agreed to the following three statements $(1=$ strongly disagree, $7=$ strongly agree): "I identify with The Blue Team," "I feel connected with The Blue Team," and "I feel committed to The Blue Team." These three items were averaged into a reliable identification scale $(\alpha=.92)$. Finally, we asked participants how they believed that other participants were treated with the following question: "Do you believe that other participants were able to voice their opinions?" $(1=$ certainly not, $7=$ certainly $)$. 
To check the status manipulation, we asked participants to what extent they agreed with the following six statements $(1=$ strongly disagree, $7=$ strongly agree $)$ : "With my individual performance on the tasks I had contributed the most to the performance of The Blue Team," "With my individual performance on the tasks I had contributed the least to the performance of The Blue Team" (recoded), "Because of my individual performance on the tasks I was the highest in status within The Blue Team," "Because of my individual performance on the tasks I was the lowest in status within The Blue Team" (recoded), "Because of my individual performance on the tasks I have been important for The Blue Team," and "Because of my individual performance on the tasks I have been unimportant for The Blue Team" (recoded). These six items were averaged into a reliable status check scale $(\alpha=.77)$. To check the status-unknown condition we asked all participants to what extent they agreed to the following three statements $\quad(1=$ strongly disagree, $7=$ strongly agree): "I do not know to what extent my individual performance on the tasks had contributed to the performance of The Blue Team," "I do not know what status I have within The Blue Team," and "I do not know to what extent I have been important for The Blue Team." These three items were averaged into a reliable status-unknown check scale $(\alpha=.87)$.

Finally, we checked the procedure manipulation with the following two items $(1=$ not at all, $7=$ very much $)$ : "Did you receive an opportunity to voice your opinion about the allocation of the lottery tickets to The Blue Team?" and "To what extent did the experimenter allow you an opportunity to voice your opinion about the allocation of the lottery tickets to The Blue Team?" These two items were strongly correlated $(r=.92, p<.001)$ and we averaged them into a reliable procedure check scale $(\alpha=.96)$. After this, participants were fully debriefed, thanked, and paid for their participation.

\section{Results}

\section{Manipulation checks}

The experimental manipulations were checked by means of $4 \times 2$ ANOVAs. On the status check scale we found a significant main effect of status only, $F(3,163)=45.81, p<.001$. A LSD test $(p<.05)$ with status as independent variable showed that participants in the low status condition $(M=3.11, S D=1.23)$ perceived themselves to have significantly lower intragroup status than participants in the average status condition $(M=4.44, S D=0.54)$, who in turn perceived themselves to have a significantly lower intragroup status than participants in the high status condition $(M=5.40$, $S D=1.09$; all $p \mathrm{~s}<.001)$. Participants in the statusunknown condition scored close to the mean of this scale $(M=4.41, S D=0.54)$ and differed significantly from the low and the high status conditions $(p s<.001)$. Further- more, it can be noted here that the mean in the average condition was significantly higher than the scale midpoint of $4, F(1,167)=9.32, p<.01$. Thus, participants in the average status condition rated their intragroup status as moderately positive in our experiment (although they were less positive than participants in the high status condition, as evidenced by the LSD tests described earlier). The only condition in which participants were negative about their status position was the low status condition, in which the mean was well below the scale midpoint of 4 , $F(1,167)=40.50, p<.001$. These results show that participants perceived the status manipulation as intended.

On the status unknown check scale we found a significant main effect of status only, $F(3,163)=17.03, p<.001$. A LSD test $(p<.05)$ with status as the independent variable showed that participants in the status unknown condition agreed significantly more with the statements that they did not know their intragroup status $(M=6.23$, $S D=1.14$ ) than participants in the low, average, and high status conditions $(M=3.93, \quad S D=1.14 ; \quad M=4.33$, $S D=1.86 ; M=4.01, S D=1.92 ;$ respectively; $p s<.001$ ). There were no significant differences between any of the low, average, and high status conditions on this measure. These findings indicate that the distinction between status known versus status unknown was induced as intended.

On the procedure check scale we found a significant main effect of procedure only, $F(1,163)=1794.14$, $p<.001$. Participants in the voice condition indicated that they had received more opportunities to voice their opinions about the allocation of the lottery tickets to The Blue Team $(M=6.37, S D=0.73)$ than participants in the no-voice condition $(M=1.26, S D=0.83)$. From these analyses, we can conclude that the participants had perceived the experimental manipulations as intended.

\section{Voiced opinions}

We then analyzed the opinions that participants expressed when they received a voice procedure. An ANOVA in the voice condition showed that the status manipulation did not affect participants' voiced opinions about how lottery tickets should be distributed between the teams, $F(3,82)=1.04, p>.37$ (overall $M=28.07$, $S D=14.47)$. Thus, participants in the high, average, low, and unknown conditions did not differ in their opinions about how lottery tickets should be divided between the teams. This demonstrates that participants' intragroup status position did not influence their opinions about the percentage of lottery tickets that The Blue Team should receive, as was intended with this manipulation.

\section{Procedural entitlement}

A $2 \times 4$ ANOVA on the procedural entitlement scale showed no significant results (all $p \mathrm{~s}>.28$; overall $M=5.15, S D=1.53$ ). Thus, participants in the various status positions did not differ significantly in the extent to which they felt entitled to fair procedures. This finding 
is in correspondence with arguments by Lind (2001) and Tyler et al. (1997; p. 119), who posited that, whereas status may lead people to feel entitled to certain outcomes (Feather, 1994), status does not influence the extent to which people feel entitled to fair procedures. These analyses showed that the current results cannot be explained by differences in perceived procedural entitlement as function of the status manipulation.

\section{Group belongingness and identification}

A $2 \times 4$ MANOVA on the belongingness and identification scales showed no significant effects on both the multivariate and univariate levels (multivariate $p \mathrm{~s}>.28$; univariate $p \mathrm{~s}>.30$; belongingness overall $M=4.35$, $S D=1.48$; identification overall $M=3.73, S D=1.63$ ). Thus, the status manipulation did not influence participants' perceived belongingness or their identification with the group. These results are consistent with previous research findings by Ellemers, Van Knippenberg, De Vries, and Wilke (1988), who showed that intragroup status does not influence identification if group boundaries are impermeable (i.e., no intergroup mobility is possible or made salient, as was the case in the current experiments). These results showed that belongingness and identification cannot explain the data that are presented in this experiment.

\section{Treatment of other participants}

An ANOVA on the question whether or not participants believed that other participants were able to voice their opinions, we found a main effect of procedure, $F(1,163)=114.53, p<.001$. Participants in the voice condition believed more strongly that others were allowed an opportunity to voice their opinions $(M=6.28$, $S D=1.30)$ than participants in the no-voice condition $(M=3.54, S D=1.95)$. Importantly, the main effect of status and the interaction were nonsignificant ( $p$ s > .37). Thus, the status manipulation did not influence participants' expectations of (un)equal treatment.

\section{Procedure judgments}

The cell means and standard deviations are presented in Table 2. An ANOVA on the procedure judgments scale showed significant main effects of procedure, $F(1,163)=187.96, \quad p<.001$, and intragroup status, $F(3,163)=2.81, p<.05$. These main effects were qualified

Table 2

Means and standard deviations of participants' procedure judgments as a function of intragroup status and procedure (Experiment 2)

\begin{tabular}{|c|c|c|c|c|c|c|c|c|}
\hline \multirow[t]{3}{*}{ Procedure } & \multicolumn{8}{|c|}{ Intragroup status } \\
\hline & \multicolumn{2}{|c|}{ High } & \multicolumn{2}{|c|}{ Average } & \multicolumn{2}{|l|}{ Low } & \multicolumn{2}{|c|}{ Unknown } \\
\hline & $M$ & $S D$ & $M$ & $S D$ & $M$ & $S D$ & $M$ & $S D$ \\
\hline Voice & 5.26 & 1.06 & 5.91 & 0.89 & 5.43 & 1.19 & 5.17 & 1.58 \\
\hline No voice & 2.44 & 1.30 & 2.97 & 1.08 & 2.06 & 1.29 & 3.40 & 1.71 \\
\hline
\end{tabular}

Note. Higher means indicate more positive procedure judgments. by the predicted interaction between intragroup status and procedure, $F(3,163)=2.97, p<.04$.

To test whether the effect of procedure was significantly stronger when participants had information about their intragroup status than when participants did not have information about their intragroup status, we conducted an interaction contrast analysis in which we tested the effect of procedure in the status unknown condition versus the status known conditions (i.e., the low, average, and high status conditions). This analysis showed a significant interaction contrast, $F(1,167)=7.82, p<.01$. Furthermore, we tested whether the procedure manipulation had different effects in the status-known conditions by means of a 2 (procedure: voice vs. no-voice) $\times 3$ (intragroup status: high vs. average vs. low) ANOVA. The interaction was nonsignificant, $F<1$, demonstrating that procedure effects were similar in the status known conditions: Participants in the high, average, and low status conditions did not differ in their reactions to the procedure manipulation. Subsequent analyses showed that the procedure simple main effect was stronger in the status known conditions, $F(1,167)=170.17, p<.001, \eta^{2}=.51$, than in the status unknown condition, $F(1,167)=20.81, p<.001, \eta^{2}=.11$. In support of Hypothesis 1, participants who had information about their intragroup status responded more strongly to voice as opposed to no-voice procedures than participants who did not have information about their intragroup status. Furthermore, the finding that the status known conditions produced the same procedure effects supported Hypothesis 2. These results correspond to the findings that were obtained in Experiment 1.

It can further be noted here that, in further correspondence with Experiment 1, simple main effect analyses showed that the intragroup status manipulation did not affect procedure judgments of participants in the voice condition, $F<1$, and did influence procedure judgments of participants in the no-voice condition, $F(3,163)=4.79, p<.01$. To further explore these effects we contrasted within each procedure condition the procedure judgments of participants who had versus had no information about their intragroup status. Results showed that the absence versus presence of intragroup status information did not affect participants' procedure judgments following voice procedures, $F<1$, but did influence procedure judgments following no-voice procedures, $F(1,163)=7.20, p<.01$. As in Experiment 1, intragroup status information particularly enhanced participants' reactions to no-voice procedures. We elaborate on this in General discussion.

\section{General discussion}

In correspondence with Hypothesis 1, the results of two experiments indicated that information about 
intragroup status enhances people's reactions to voice as opposed to no-voice procedures. In the high, average, and low intragroup status conditions, we consistently found stronger effects of variations in voice procedures on participants' procedure judgments than in the control condition, where participants had no information about their intragroup status position. The two reported experiments therefore suggested that people's reactions to procedures are moderated by the absence versus presence of intragroup status information. The moderating effect of the absence versus presence of status information is consistent with the findings reported in Van Prooijen et al. (2002) in which it was shown that salience of the general concept status was sufficient to enhance reactions to procedural justice. Taken together, the current findings and the Van Prooijen et al. (2002) data suggest that informing people about their specific intragroup status position makes the general concept status salient, regardless of whether intragroup status is low, average, or high. The finding that the effects of voice as opposed to no-voice procedures were enhanced in the high, the average, and the low status conditions may therefore imply that salience of the concept status constitutes a primary explanation for relations between status and procedural justice in intragroup settings.

The current data did not provide evidence for a difference in reactions to procedures between high versus low status individuals, as was predicted in Hypothesis $2_{\text {alt }}$. Moreover, in correspondence with research by Ellemers et al. (1988), in Experiment 2 we found no effects of the status manipulation on belongingness and identification. This contradicts the alternative proposition that low status members needed to be reassured of their belongingness to the group, the proposition that led to Hypothesis $2_{\text {alt }}$. The current findings are in correspondence with Hypothesis 2, and the fact that we did find the predicted moderating effect of the absence versus presence of status information suggests that, at least in the current research, status salience is a more potent explanation of the relation between intragroup status and procedural justice than possible differences in level of status positions.

Nevertheless, we note here that scientists should not be too ready in concluding that differences between status positions on reactions to procedures can never be found. For example, it could be that status differences based on issues that are more centrally located in the self-concept than was the case in the current studies do lead to differences in reactions to procedures. Furthermore, it is noteworthy that in the present experiments nobody could be excluded from the group (i.e., exclusion was impossible in Experiment 2, and the possibility of exclusion was not made salient in Experiment 1). As such, it could be the case that there was no need for low status individuals to feel insecure of their belongingness in the group, given that they did not expect to be cast out of the group. In correspondence with this line of reasoning, Ellemers et al. (1988) found no effects of intragroup status on identification if intergroup mobility was impossible, but they did find effects of intragroup status on identification if intergroup mobility was possible. By derivation, it can thus be predicted that the difference between high and low status members in procedural influence does materialize in situations where low status members can be degraded to lower status groups, or where high status members can be promoted to higher status groups. These issues are interesting directions for future research to pursue.

The current studies did not find evidence for Hypothesis $1_{\text {alt }}$, which stated that the effects of procedures would be weaker when status information was available than when status information was unavailable. This hypothesis was based on fairness heuristic theory's proposition of the fairness substitutability effect (e.g., Van den Bos et al., 1998; Van den Bos \& Lind, 2002). A possible explanation for the fact that we could not find evidence for a substitutability effect in the relation between status and procedural justice is the group-dynamic context in which the hypotheses were tested. In previous fairness heuristic and uncertainty management experiments, participants were typically not placed in social groups, as we did in the current experiments. Furthermore, it has been found before that fairness heuristic theory's and uncertainty management model's predictions could not be corroborated in group paradigms (see Van den Bos \& Lind, 2001; Van Prooijen et al., 2004a). It could therefore be the case that the processes advanced by fairness heuristic theory and the uncertainty management model are less generalizable to group-dynamic contexts than has been recognized before. Nevertheless, the current research should not be conceived of as a refutation of fairness heuristic theory and the uncertainty management model. There are more studies that support fairness heuristic and uncertainty management predictions (e.g., Van den Bos, 2001; Van den Bos \& Miedema, 2000; Van den Bos, Poortvliet, Maas, Miedema, \& Van den Ham, 2005; Van den Bos, Lind, Vermunt, \& Wilke, 1997; Van den Bos, Vermunt, \& Wilke, 1997; Van den Bos et al., 1998; for an overview, see Van den Bos \& Lind, 2002) than studies that do not support fairness heuristic and uncertainty management predictions (cf. the current paper; Van den Bos \& Lind, 2001; Van Prooijen et al., 2004a). Future research would do well to explore conditions under which the processes advanced by fairness heuristic theory and the uncertainty management model do or do not operate.

We operationalized no-voice procedures by explicitly denying participants the opportunity to voice their opinions. It was important to do so, because it has been found before that explicit denial of voice is more successful in inducing experiences of procedural unfairness as compared with more implicit no-voice procedures (i.e., 
not mentioning the possibility of having voice; see Van den Bos, 1999, 2003). In the current experiments, the explicit denial of voice had implications for participants' reactions to the status manipulation: inspection of the data presented here reveals that predominantly participants who were denied voice (and not those who received voice) were affected by the intragroup status manipulation. That is, in both experiments information about status significantly affected the reactions of participants who had received a no-voice procedure compared with the control condition. This corresponds to previous statements in the literature that negative procedures might exert stronger negative effects on people's reactions than that positive procedures exert positive effects, and that people seem to be affected more by procedural injustice than by procedural justice (e.g., Folger, 1984; Folger \& Cropanzano, 1998; Van den Bos \& Van Prooijen, 2001; see also Brockner \& Wiesenfeld, 1996; Van den Bos et al., 1997; cf. Skowronski \& Carlston, 1989). These findings have led some authors to conclude that it may be more accurate to talk about a no-voice effect as opposed to a voice effect (Van den Bos \& Van Prooijen, 2001). The present findings have shown similar results: stronger reactions to status information when participants were denied a voice opportunity than when they received such an opportunity. This suggests that intragroup status predominantly influences people's reactions to unfair procedures.

Manipulation checks in Experiment 2 showed that relative task performance was a successful operationalization of intragroup status (Tyler \& Blader, 2002; cf. Van Prooijen et al., 2004b). Nevertheless, it is possible that manipulating task performance might also influence other variables, such as self-efficacy and mood. It is important to note here that, in light of previous research findings, it is unlikely that these variables explain the current results. First, previous research has shown that people who are highly capable of providing meaningful input in a decision-making process (which is closely associated with the self-efficacy construct) respond more strongly to voice as opposed to no-voice procedures than people who are low capable of providing meaningful input (Brockner et al., 1998). This does not correspond with the current findings, where high status individuals responded equally strong to procedures as low status individuals. Second, previous research has shown that mood only influences procedural fairness judgments if people do not have information about procedures (Van den Bos, 2003). However, in the current experiment all participants had information about the procedure they received (i.e., participants received either a voice or a no-voice procedure). Moreover, Van Prooijen et al. (2002) had assessed a mood measure, and this measure could not explain the relation between status and procedural justice. Taken together, the most plausible explanation of the current results is that the avail- ability of status information makes the concept status salient, as argued in this article (cf. Van Prooijen et al., 2002).

As noted in the introduction, distributive justice research has related intragroup status to perceptions of entitlement (Feather, 1994): people with high intragroup status often are entitled to higher outcomes than people with low intragroup status. As a consequence, different outcome distributions may be fair depending on people's status positions. It is important to note that these arguments refer to distributive justice, not to procedural justice. It is less likely that social status affects the extent to which people perceive themselves to be entitled to fair procedures. As emphasized by Lind (2001), people at all levels of group hierarchies value fair procedures as such procedures affirm that people are respected and valued by the social groups they belong to (see also Tyler et al., 1997, p. 119). In other words, fair procedures convey relational benefits that are important to members at all levels of group hierarchies (see also Huo, 2002). Furthermore, we did not find that the effects of voice as opposed to no-voice procedures were strongest in the high status condition, which would be expected if high status individuals perceived themselves as most entitled to fair procedures. In addition, in Experiment 2 we measured the extent to which participants felt entitled to fair procedures, and this measure was unaffected by the status manipulation. These considerations suggest that the current findings cannot be explained by perceptions of entitlement.

To return to the concepts that motivated the current contribution, it can be concluded that the present studies have shown new insights in the psychology of intragroup status and procedural justice. Information about people's intragroup status position enhances their reactions to voice as opposed to no-voice procedures. This suggests that status salience may help to explain the relation between status and procedural justice in an intragroup context. Knowing where we stand in a group, to the extent that it makes one's intragroup status salient, thus enhances reactions to procedural justice.

\section{References}

Adams, J. S. (1965). Inequity in social exchange. In L. Berkowitz (Ed.), Advances in Experimental Social Psychology (Vol. 2, pp. 267-299). New York: Academic Press.

Aron, A., Aron, E. A., \& Smollan, D. (1992). Inclusion of other in the self scale and the structure of interpersonal closeness. Journal of Personality and Social Psychology, 63, 596-612.

Brewer, M. B. (1979). In-group bias in the minimal intergroup situation: A cognitive-motivational analysis. Psychological Bulletin, 86 , 307-324.

Brockner, J., Heuer, L., Siegel, P. A., Wiesenfeld, B., Martin, C., Grover, S., Reed, T., \& Bjorgvinsson, S. (1998). The moderating effect of self-esteem in reaction to voice: Converging evidence from five studies. Journal of Personality and Social Psychology, 75, 394-407. 
Brockner, J., \& Wiesenfeld, B. M. (1996). An integrative framework for explaining reactions to decisions: Interactive effects of outcomes and procedures. Psychological Bulletin, 120, 189-208.

Cropanzano, R., Byrne, Z. S., Bobocel, D. R., \& Rupp, D. E. (1997). Moral virtues, fairness heuristics, social entities, and other denizens of organizational justice. Journal of Vocational Behavior, 58, 164 209.

Cropanzano, R., Rupp, D. E., Mohler, C. J., \& Schminke, M. (2001). Three roads to organizational justice. In J. Ferris (Ed.), Review of Personnel and Human Resources Management (Vol. 20, pp. 1-113). Greenwich, CT: JAI Press.

De Cremer, D. (2002). Respect and cooperation in social dilemma's: The importance of feeling included. Personality and Social Psychology Bulletin, 28, 1335-1341.

Ellemers, N., Van Knippenberg, A., De Vries, N., \& Wilke, H. A. M. (1988). Social identification and permeability of group boundaries. European Journal of Social Psychology, 18, 497-513.

Feather, N. (1994). Attitudes toward high achievers and reactions to their fall: Theory and research concerning tall poppies. In M. P. Zanna (Ed.), Advances in Experimental Social Psychology (Vol. 26, pp. 1-73). San Diego, CA: Academic Press.

Folger, R. (1977). Distributive and procedural justice: Combined impact of "voice" and improvement on experienced inequity. Journal of Personality and Social Psychology, 35, 108-119.

Folger, R. (1984). Emerging issues in the social psychology of justice. In R. Folger (Ed.), The sense of injustice: Social psychological perspectives (pp. 3-24). New York: Plenum.

Folger, R., \& Cropanzano, R. (1998). Organizational justice and human resource management. Thousand Oaks, CA: Sage.

Folger, R., Rosenfield, D., Grove, J., \& Corkran, L. (1979). Effects of "voice" and peer opinions on responses to inequity. Journal of Personality and Social Psychology, 37, 2253-2261.

Greenberg, J., \& Folger, R. (1983). Procedural justice, participation, and the fair process effect in groups and organizations. In P. B. Paulus (Ed.), Basic group processes (pp. 235-256). New York: Springer-Verlag.

Huo, Y. J. (2002). Justice and the regulation of social relations: When and why do group members deny claims to social goods. British Journal of Social Psychology, 41, 535-562.

Lind, E. A. (2001). Thinking critically about justice judgments. Journal of Vocational Behavior, 58, 220-226.

Lind, E. A., Kanfer, R., \& Earley, P. C. (1990). Voice, control, and procedural justice: Instrumental and noninstrumental concerns in fairness judgments. Journal of Personality and Social Psychology, 59, 952-959.

Lind, E. A., Kulik, C. T., Ambrose, M., \& De Vera Park, M. V. (1993). Individual and corporate dispute resolution: Using procedural fairness as a decision heuristic. Administrative Science Quarterly, 38, 224-251.

Lind, E. A., \& Tyler, T. R. (1988). The social psychology of procedural justice. New York: Plenum.

Skowronski, J. J., \& Carlston, D. E. (1989). Negativity and extremity biases in impression formation: A review of explanations. Psychological Bulletin, 105, 131-142.

Tajfel, H., \& Turner, J. C. (1979). An integrative theory of intergroup conflict. In W. G. Austin \& S. Worchel (Eds.), The social psychology of intergroup relations (pp. 33-47). Monterey, CA: Brooks/Cole.

Thibaut, J., \& Walker, L. (1975). Procedural justice: A psychological analysis. Hillsdale, NJ: Erlbaum.

Tyler, T. R. (1989). The psychology of procedural justice: A test of the group-value model. Journal of Personality and Social Psychology, $57,830-838$.

Tyler, T. R. (1994). Psychological models of the justice motive: Antecedents of distributive and procedural justice. Journal of Personality and Social Psychology, 5, 850-863.

Tyler, T. R., \& Blader S. L. (2000). Cooperation in groups: Procedural justice, social identity, and behavioral engagement, Taylor \& Francis Group.
Tyler, T. R., \& Blader, S. L. (2002). Autonomous vs. comparative status: Must we be better than others to feel good about ourselves? Organizational Behavior and Human Decision Processes, 89, 813838 .

Tyler, T. R., Boeckmann, R. J., Smith, H. J., \& Huo, Y. J. (1997). Social justice in a diverse society, Westview Press.

Tyler, T. R., Degoey, P., \& Smith, H. (1996). Understanding why the justice of group procedures matters: A test of the psychological dynamics of the group-value model. Journal of Personality and Social Psychology, 70, 913-930.

Tyler, T. R., \& Lind, E. A. (1992). A relational model of authority in groups. In M. Zanna (Ed.), Advances in Experimental Social Psychology (Vol. 25, pp. 115-292). San Diego, CA: Academic Press.

Tyler, T. R., \& Smith, H. J. (1998). Social justice and social movements. In T. Gilbert, S. T. Fiske, \& G. Lindsey (Eds.), The handbook of social psychology (Vol. 2, pp. 595-629). New York: McGraw-Hill.

Van den Bos, K. (1999). What are we talking about when we talk about no-voice procedures. On the psychology of the fair outcome effect. Journal of Experimental Social Psychology, 35, 560-577.

Van den Bos, K. (2001). Uncertainty management: The influence of human uncertainty on reactions to perceived fairness. Journal of Personality and Social Psychology, 80, 931-941.

Van den Bos, K. (2003). On the subjective quality of social justice: The role of affect as information in the psychology of justice judgments. Journal of Personality and Social Psychology, 85, 482-498.

Van den Bos, K., \& Lind, E. A. (2001). The psychology of own versus others' treatment: Self-oriented and other-oriented effects on perceptions of procedural justice. Personality and Social Psychology Bulletin, 27, 1324-1333.

Van den Bos, K., \& Lind, E. A. (2002). Uncertainty management by means of fairness judgments. In M. P. Zanna (Ed.), Advances in Experimental Social Psychology (Vol. 34, pp. 1-60). San Diego, CA: Academic Press.

Van den Bos, K., Lind, E. A., Vermunt, R., \& Wilke, H. A. M. (1997). How do I judge my outcome when I do not know the outcome of others? The psychology of the fair process effect. Journal of Personality and Social Psychology, 72, 1034-1046.

Van den Bos, K., Lind, E. A., \& Wilke, H. A. M. (2001). The psychology of procedural and distributive justice viewed from the perspective of fairness heuristic theory. In R. Cropanzano (Ed.), Justice in the workplace: Volume 2-From theory to practice (pp. 49-66). Mahwah, NJ: Erlbaum.

Van den Bos, K., \& Miedema, J. (2000). Toward understanding why fairness matters: The influence of mortality salience on reactions to procedural fairness. Journal of Personality and Social Psychology, $79,355-366$

Van den Bos, K., Poortvliet, P. M., Maas, M., Miedema, J., \& Van den Ham, E.-J. (2005). An enquiry concerning the principles of cultural norms and values: The impact of uncertainty and mortality salience on reactions to violations and bolstering of cultural worldviews. Journal of Experimental Social Psychology, 41, 91-113.

Van den Bos, K., \& Van Prooijen, J.-W. (2001). Referent cognitions theory: The psychology of voice depends on closeness of reference points. Journal of Personality and Social Psychology, 81, 616-626.

Van den Bos, K., Vermunt, R., \& Wilke, H. A. M. (1997). Procedural and distributive justice: What is fair depends more on what comes first than on what comes next. Journal of Personality and Social Psychology, 72, 95-104.

Van den Bos, K., Wilke, H. A. M., \& Lind, E. A. (1998). When do we need procedural fairness. The role of trust in authority. Journal of Personality and Social Psychology, 75, 1449-1458.

Van den Bos, K., Wilke, H. A. M., Lind, E. A., \& Vermunt, R. (1998). Evaluating outcomes by means of the fair process effect: Evidence for different processes in fairness and satisfaction judgments. Journal of Personality and Social Psychology, 74, 1493-1503.

Van Leeuwen, E., Van Knippenberg, D., \& Ellemers, N. (2003). Continuing and changing group identities: The effects of merging on social 
identification and ingroup bias. Personality and Social Psychology Bulletin, 29, 679-690.

Van Prooijen, J.-W., Van den Bos, K., \& Wilke, H. A. M. (2002). Procedural justice and status: Status salience as antecedent of procedural fairness effects. Journal of Personality and Social Psychology, 83, 1353-1361.

Van Prooijen, J.-W., Van den Bos, K., \& Wilke, H. A. M. (2004a). Group belongingness and procedural justice: Social inclusion and exclusion by peers affects the psychology of voice. Journal of Personality and Social Psychology, 87, 66-79.

Van Prooijen, J.-W., Van den Bos, K., \& Wilke, H. A. M. (2004b). The role of standing in the psychology of procedural justice: Towards theoretical integration. In Stroebe W. \& M. Hewstone (Eds.), European Review of Social Psychology (Vol. 15, pp. 33-58). East Sussex, UK: Psychology Press. 